INDONESIA ACCOUNTING JOURNAL

VOLUME 2, NUMBER 2, YEAR 2020

${ }^{1}$ Corresponding author

Jurusan Akuntansi

Fakultas Ekonomi dan Bisnis

Universitas Sam Ratulangi

Jl. Kampus UNSRAT

Manado, Indonesia, 95115

E-mail: vicy.dasmasela@gmail.com

${ }^{2,3}$ Jurusan Akuntansi

Fakultas Ekonomi dan Bisnis

Universitas Sam Ratulangi

Jl. Kampus UNSRAT

Manado, Indonesia, 95115

Article info:

Received 29 January 2020

Accepted 29 January 2020

Available online 29 January 2020

Keywords: total quality management; defects product

JEL Classification: M11, M14

DOI: http://doi.org/10.32400/iaj.27796

\section{Penerapan Total Quality Management terhadap produk cacat pada PT. Sinar Pure Fonds International di Bitunge}

\author{
Vicy M. Dasmasela ${ }^{1}$ \\ Jenny Morasa ${ }^{2}$ \\ Sintje Rondonuwu ${ }^{3}$
}

\begin{abstract}
Total quality management is a philosophy that requires changes in behavior at all levels of the organization with attention on the importance of consumer satisfaction. Or in other words, the improvement of which is carried out continuously by every person in the organization to understand, meet and even exceed customer expectation. This study aims to determine how the implementation of total quality management to defects product in the PT. Sinar Pure Foods International in Bitung. Type of research used in this thesis research is descriptive research type. The type of data used in this research is qualitative data. The results of the study found that quality is an important factor in a company especially in the production. Total quality management has been applied effectively on PT. Sinar Pure Foods International in Bitung.
\end{abstract}

\section{Pendahuluan}

Kompetisi yang lebih ketat memberikan berbagai keuntungan berupa tersedianya barang dan jasa yang lebih beraneka ragam, dengan kualitas lebih baik, dan harga lebih murah. Hal inilah yang menuntut para pelaku bisnis harus berpikir cerdik agar dapat memberikan manfaat kepada pelanggan dan senantiasa konsisten dalam menurunkan biaya sehingga dapat meningkatkan nilai kepada pelanggan seiring dengan penciptaan laba perusahaan. Tujuan kualitas yaitu tingkat kinerja yang harus dicapai oleh suatu individu atau organisasi yang ditetapkan dengan jelas sehingga membuat individu atau pun kelompok mengerti apa yang harus dikerjakan agar kinerja mereka meningkat dan dapat mencapai tujuan perusahaan (Butarbutar et al., 2017).

Total Quality Management (TQM) adalah sebuah pendekatan yang banyak digunakan oleh perusahaan dalam meningkatkan kualitas secara sistematis dengan tujuan meningkatkan kinerja seperti kualitas, produktivitas dan profitabilitas. Untuk dapat diperoleh dan mempertahankan kelangsungan hidup perusahaan dalam menghadapi persaingan yang kompetitif, diperlukan suatu komitmen perusahaan yang mengarah kepada kepuasan pelanggan, dimana mutu merupakan faktor utama yang mempengaruhi pilihan konsumen untuk berbagai jenis produk dan jasa. Selain itu, Total Quality Management juga memiliki prinsip yang menghargai setiap orang yang terlibat untuk memberikan pendapat demi perbaikan perusahaan secara berkesinambungan.

\section{Tinjauan pustaka}

Akuntansi. Akuntansi dilaksanakan baik dalam entitas yang bertujuan memperoleh laba maupun dalam organisasi yang tidak mencari laba. Akuntansi dilakukan dalam berbagai organisasi dengan 
alasan karena semakin rumitnya variabelvariabel yang dihadapi para manajer walaupun dalam entitas kecil. Keadaan ini mengakibatkan para manajer dan pihak yang memerlukan informasi keuangan semakin tergantung pada proses akuntansi, dimana transaksi-transaksi entitas diubah menjadi data statistik dan ringkas serta dilaporkan dalam bentuk laporan keuangan (Hutauruk, 2019). Secara umum, akuntansi adalah suatu sistem informasi yang dapat memberikan laporan berupa kondisi keuangan ataupun hasil kinerja kepada para pengguna informasi akuntansi atau pihak-pihak yang berkepentingan atau stakeholders (Hery, 2014). Pengertian akuntansi lainnya yaitu akuntansi sebagai suatu sistem informasi yang mengelola data-data dan memaparkannya berupa sekumpulan laporan kepada pihak-pihak yang terkait dengan aktifitas-aktifitas ekonomi dan kondisi bisnis dalam suatu perusahaan. Dari berbagai uraian diatas, akuntansi dapat didefinisikan sebagai suatu sistem informasi yang berisi kegiatan atau aktifitas perusahaan yang bertujuan menghasilkan laporan keuangan sebagai dasar pengambilan keputusan (Dewi, 2017). Akuntansi juga dapat didefinisikan sebagai sistem informasi yang dapat mengukur suatu aktifitas bisnis dan dapat mengolah data menjadi sebuah laporan, kemudian memberikan hasilnya kepada para pengambil keputusan (Jusup, 2014). Tujuan dari pelaporan keuangan adalah untuk memberikan informasi yang berguna bagi investor dan kreditur dalam pengambilan keputusan investasi dan kredit. Jenis keputusan yang dibuat oleh pengambil keputusan sangatlah beragam, begitu juga dengan metode pengambilan keputusan yang mereka gunakan dan kemampuan mereka untuk memproses informasi (Hery, 2017).

Akuntansi manajemen. Akuntansi manajemen adalah salah satu bidang ilmu akuntansi yang mempelajari bagaimana fokus hanya pada penyediaan termasuk pengembangan dan penafsiran informasi akuntansi yang berguna bagi para manajer sebagai bahan perencanaan, pengendalian operasi dan dalam pengambilan keputusan
(Samryn, 2015). Akuntansi manajemen mengukur, menganalisis, dan melaporkan informasi keuangan serta non keuangan yang membantu manajer untuk membuat keputusan yang bermanfaat demi tercapainya tujuan organisasi. Manajer akan menggunakan informasi akuntansi manajemen untuk memilih, mengkomunikasikan, dan mengimplementasikan strategi serta untuk mengkoordinasikan keputusan produksi dan pemasaran. Akuntansi manajemen memusatkan perhatian pada pelaporan informasi untuk pengguna internal. Yang dimaksud dengan pihak internal yaitu para manajer diberbagai jenjang (tingkatan) dalam organisasi. Informasi ini akan dikonsumsi oleh para manajer tersebut guna melaksanakan tugas-tugas sebagai seorang manajer yang lebih berorientasi pada penyusunan anggaran untuk masa depan (Hery, 2015). Sistem akuntansi manajemen tidak hanya digunakan untuk mencatat transaksi keuangan yang telah terjadi saja, namun sangat berperan dalam melakukan bisnis. Jadi dalam akuntansi manajemen, informasi yang dihasilkan ialah informasi yang sebenarnya belum terjadi namun diharapkan akan terjadi dimasa yang akan datang (Tengor et al., 2016). Tidak ada satu lembaga yang mengatur dan mengharuskan sebuah organisasi perusahaan untuk menyelenggarakan akuntansi manajemen karena informasi yang dihasilkan atas dasar manfaat bagi manajemen dan bukan atas dasar permintaan (Sujarweni, 2015). Dengan demikian, akuntansi manajemen adalah proses identifikasi, pengukuran, pengumpulan, analisis, pencatatan, interpretasi dan pelaporan berbagai kejadian ekonomi dalam kegiatan usaha yang digunakan oleh manajemen dalam menjalankan fungsi manajemen (Rachmina dan Sari, 2015).

Manajemen Mutu Terpadu (Total Quality Management/TQM). Total Quality Management adalah filosofi yang menghendaki perubahan perilaku pada semua tingkat organisasi dengan menaruh perhatian pada pentingnya kepuasan konsumen. Atau dengan kata lain, 
peningkatan yang dilakukan secara terus menerus oleh setiap orang dalam organisasi untuk memahami, memenuhi bahkan melebihi harapan pelanggan. Filosofi total quality management ini menekankan pada sumber daya manusia dan hubungan antar manusia yang tidak hanya mengandalkan pemeriksaan kualitas pada akhir proses, tetapi lebih menitikberatkan pada proses pembentukan kualitas itu sendiri dengan cara menghilangkan penyimpanganpenyimpangan yang terjadi selama proses produksi (Santioso dan Maharani, 2015). Umumnya ada dua cara pelaksanaan pengawasan terhadap kualitas produk. Cara pertama, dengan mengawasi proses produksi terus-menerus. Dalam hal ini penyesuaian dan koreksi dilaksanakan segera sebelum terlalu banyak kerusakan yang terjadi. Cara kedua, dengan mengawasi tingkat kualitas dari hasil sehingga produk cacat yang dihasilkan semakin sedikit dan dapat mengurangi biaya perbaikan (Yuliansih et al., 2014).

Kualitas. Kualitas merupakan kekuatan terpenting yang memberikan keberhasilan suatu organisasi dan pertumbuhan perusahaan baik di pasar berskala nasional maupun internasional. Sehingga tiap perusahaan selalu berupaya mengembangkan produknya dalam menghadapi persaingan di pasar bebas. Seiring perkembangan teknologi, banyak terobosan baru yang dikembangkan oleh produsen yang intinya adalah untuk meningkatkan kualitas produk (Helmi, 2016).

Produk cacat. Definisi dari produk cacat yaitu merupakan unit-unit produk yang karena keadaan fisiknya tidak dapat dilakukan sebagai produk akhir, tetapi dapat diperbaiki untuk kemudian dijual dalam bentuk produk akhir. Dalam proses produksi, produk cacat ini dapat diakibatkan oleh dua hal, yaitu disebabkan oleh spesifikasi pemesanan dan disebabkan oleh faktor internal. Permasalahan yang muncul atas produk cacat ini adalah perlakuan terhadap pengerjaan kembali atau rework (Helmi, 2016). Cacat memiliki pengertian kekurangan yang menyebabkan nilai atau mutunya kurang baik atau kurang sempurna. Produk cacat berarti barang atau jasa yang dibuat dalam proses produksi namun memiliki kekurangan yang menyebabkan nilai atau mutunya kurang baik atau kurang sempurna (Janah, 2017).

\section{Metode penelitian}

Jenis penelitian yang digunakan yaitu penelitian deskriptif. Penelitian ini bertujuan untuk menjelaskan bagaimana penerapan total quality management terhadap produk cacat pada PT. Sinar Pure Foods International di Bitung. Penelitian ini di lakukan di PT. Sinar Pure Foods International di Bitung, pada bulan Mei 2019 sampai selesai. Jenis data yang digunakan dalam penelitian ini adalah data kualitatif. Penelitian kualitatif adalah penelitian tentang riset yang cenderung menggunakan analisis dan bersifat deskriptif. Data kualitatif lebih bersifat mendalam dan terperinci, sehingga data kualitatif ini harus spesifik agar mudah dipahami oleh pihak lain. Sumber data yang digunakan adalah data primer. Data primer adalah data yang didapat secara langsung oleh peneliti melalui wawancara langsung dengan nara sumber dari PT. Sinar Pure Foods International, tentang penerapan total quality management.

Teknik pengumpulan data pada penelitian kualitatif diperoleh dari:

1. Wawancara, yaitu tanya jawab secara langsung dengan seseorang atau lebih untuk memperoleh informasi yang diinginkan. Dengan wawancara, bisa mengetahui terlebih dahulu permasalahan yang sedang terjadi. Wawancara akan dilakukan langsung dengan pihak perusahaan yang terkait.

2. Dokumen, yaitu bentuk surat yang tertulis yang bisa digunakan sebagai bukti keterangan, seperti data produk cacat periode 2015-2019 pada PT. Sinar Pure Foods International.

Metode analisis yang digunakan adalah metode analisa deskriptif. Proses analisis data yang dilakukan dalam penelitian ini ialah sebagai berikut: (1) observasi langsung ke objek penelitian yaitu PT. Sinar Pure Foods International; (2) wawancara dengan 
beberapa narasumber; (3) mengumpulkan data berupa dokumen produk cacat; (4) menghubungkan teori-teori pendukung dengan hasil penelitian; dan (5) menarik kesimpulan dan memberikan saran yang sesuai dengan kebutuhan perusahaan.

\section{Hasil penelitian dan pembahasan \\ Hasil penelitian}

Penelitian ini dilakukan pada PT. Sinar Pure Foods International di Bitung untuk mengetahui bagaimana penerapan total quality management. Tabel 1 menyajikan data produk cacat dari PT. Sinar Pure Foods International.

Tabel 1. Persentase data produk cacat periode 2015 - 2019

\begin{tabular}{|c|c|c|c|c|c|c|c|c|c|c|c|c|c|c|}
\hline \multirow{2}{*}{ Tahun } & \multirow{2}{*}{ Ket } & \multicolumn{12}{|c|}{ Bulan } & \multirow{2}{*}{ Total } \\
\hline & & Jan & Feb & Mar & Apr & Mei & Jun & Jul & Ags & Sep & Okt & Nov & Des & \\
\hline \multirow[t]{3}{*}{2015} & Qty & 25.50 & 23.10 & 21.40 & 25.50 & 23.30 & 20.20 & 15.70 & 18.50 & 27.30 & 30.80 & 26.20 & 20.10 & 23.10 \\
\hline & 603 & 0.50 & 0.83 & 0.25 & 0.20 & 0.15 & 0.15 & 0.10 & 0.25 & 0.35 & 0.15 & 0.20 & 0.10 & 0.26 \\
\hline & 307 & 0.07 & 0.05 & 0.06 & 0.04 & 0.06 & 0.09 & 0.08 & 0.07 & 0.05 & 0.05 & 0.03 & 0.04 & 0.05 \\
\hline \multirow[t]{3}{*}{2016} & Qty & 27.40 & 22.00 & 33.10 & 26.10 & 21.60 & 23.60 & 12.70 & 21.70 & 31.80 & 35.90 & 23.60 & 16.40 & 24.60 \\
\hline & 603 & 0.66 & 0.85 & 0.13 & 0.11 & 0.12 & 0.16 & 0.05 & 0.28 & 0.35 & 0.11 & 0.15 & 0.05 & 0.25 \\
\hline & 307 & 0.05 & 0.08 & 0.04 & 0.03 & 0.05 & 0.06 & 0.08 & 0.07 & 0.08 & 0.03 & 0.03 & 0.03 & 0.05 \\
\hline \multirow[t]{3}{*}{2017} & Qty & 21.80 & 22.90 & 23.90 & 24.30 & 22.30 & 21.80 & 21.60 & 22.50 & 29.70 & 25.00 & 23.10 & 21.20 & 23.30 \\
\hline & 603 & 0.10 & 0.13 & 0.04 & 0.13 & 0.10 & 0.15 & 0.12 & 0.12 & 0.14 & 0.14 & 0.15 & 0.14 & 0.12 \\
\hline & 307 & 0.09 & 0.03 & 0.05 & 0.05 & 0.02 & 0.02 & 0.03 & 0.04 & 0.06 & 0.03 & 0.04 & 0.03 & 0.04 \\
\hline \multirow[t]{3}{*}{2018} & Qty & 20.70 & 22.80 & 24.50 & 23.70 & 21.90 & 22.30 & 20.50 & 23.10 & 25.90 & 24.70 & 21.60 & 23.40 & 22.90 \\
\hline & 603 & 0.09 & 0.13 & 0.05 & 0.09 & 0.10 & 0.13 & 0.11 & 0.10 & 0.12 & 0.13 & 0.10 & 0.12 & 0.10 \\
\hline & 307 & 0.07 & 0.04 & 0.04 & 0.03 & 0.03 & 0.02 & 0.02 & 0.03 & 0.05 & 0.03 & 0.03 & 0.04 & 0.03 \\
\hline \multirow[t]{3}{*}{2019} & Qty & 21.50 & 23.70 & 20.80 & 24.50 & 22.70 & 21.60 & 23.90 & 26.90 & 24.20 & 22.10 & 20.40 & 24.40 & 23.00 \\
\hline & 603 & 0.10 & 0.11 & 0.03 & 0.07 & 0.10 & 0.09 & 0.09 & 0.10 & 0.11 & 0.08 & 0.08 & 0.11 & 0.08 \\
\hline & 307 & 0.05 & 0.04 & 0.04 & 0.02 & 0.02 & 0.03 & 0.02 & 0.04 & 0.04 & 0.03 & 0.02 & 0.03 & 0.03 \\
\hline
\end{tabular}

Sumber : PT. Sinar Pure Foods International

\section{Pembahasan}

Analisis hasil wawancara. Kualitas merupakan salah satu hal yang penting bagi perusahaan karena kualitaslah yang akan menentukan bagaimana penilaian masyarakat terhadap perusahaan, dan tanpa kualitas sebuah produk bisa dikatakan gagal. Untuk mencegah terjadinya kualitas produk yang rendah, maka PT. Sinar Pure Foods International telah menerapkan jaminan kualitas sedari awal proses produksi yaitu, mulai dari penerimaan bahan baku. Walaupun telah menetapkan jaminan kualitas sedari awal, tapi tidak menutup kemungkinan terjadinya kesalahan atau kendala dalam proses produksi. Kendala yang sering terjadi yaitu ketika produk tersebut tidak sesuai dengan standar kualitas yang ditetapkan. Tindak lanjut yang diambil yaitu memasukan semua produk yang dianggap cacat ke dalam badstock kemudian produk-produk tersebut akan di baharui atau diproduksi kembali dari awal. Berdasarkan data persentase produk cacat pada tahun 2015 dan 2019 diatas, dengan upaya yang selama ini dilakukan oleh pihak perusahaan, didapati bahwa persentase produk cacat berkurang seperti pada Tabel 2 .

Tabel 2. Total rata-rata produksi periode 2015-2019

\begin{tabular}{cccc}
\hline Tahun & Total Rata-Rata Produksi & $\mathbf{6 0 3} \mathbf{( \% )}$ & $\mathbf{3 0 7} \mathbf{( \% )}$ \\
\hline 2015 & $23.1 \mathrm{MT}$ & 0.26 & 0.05 \\
2016 & $24.6 \mathrm{MT}$ & 0.25 & 0.05 \\
2017 & $23.4 \mathrm{MT}$ & 0.12 & 0.04 \\
2018 & $22.9 \mathrm{MT}$ & 0.10 & 0.03 \\
2019 & $23.0 \mathrm{MT}$ & 0.08 & 0.03 \\
\hline
\end{tabular}

Sumber: PT. Sinar Pure Foods International 


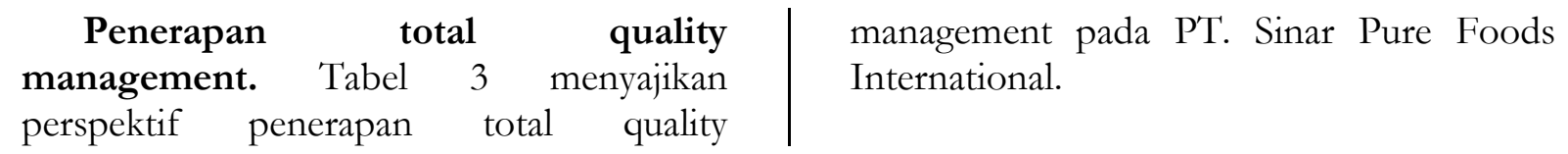

Tabel 3. Perspektif penerapan total quality management pada PT. Sinar Pure Foods International

\begin{tabular}{|c|c|c|c|c|}
\hline No & Perspektif & Tindakan & Penerapan & Aktifitas \\
\hline \multirow[t]{3}{*}{1} & \multirow[t]{3}{*}{$\begin{array}{l}\text { Organizational Practices } \\
\text { (Praktek Organisasi) }\end{array}$} & Training & $\begin{array}{c}\text { Sudah } \\
\text { diterapkan }\end{array}$ & Reorientasi \\
\hline & & Visi dan Misi & Belum & - \\
\hline & & $\begin{array}{l}\text { Prosedur Operasi yang } \\
\text { Efektif }\end{array}$ & $\begin{array}{l}\text { Sudah } \\
\text { diterapkan }\end{array}$ & Memiliki SOP \\
\hline \multirow[t]{2}{*}{2} & \multirow[t]{2}{*}{$\begin{array}{l}\text { Quality } \\
\text { dasar) }\end{array}$} & $\begin{array}{l}\text { Perbaikan } \\
\text { berkesinambungan }\end{array}$ & $\begin{array}{l}\text { Sudah } \\
\text { diterapkan }\end{array}$ & Memperbaharui produk cacat \\
\hline & & Kerja Sama & $\begin{array}{l}\text { Sudah } \\
\text { diterapkan }\end{array}$ & $\begin{array}{l}\text { Meeting diluar kantor, acara } \\
\text { kebersamaan }\end{array}$ \\
\hline 3 & $\begin{array}{l}\text { Employee Fulfillment } \\
\text { (Pemenuhan Pegawai) }\end{array}$ & $\begin{array}{l}\text { Empowerment } \\
\text { (Pemberdayaan) } \\
\text { Komitmen Organisasi }\end{array}$ & $\begin{array}{l}\text { Sudah } \\
\text { diterapkan } \\
\text { Sudah } \\
\text { diterapkan }\end{array}$ & $\begin{array}{l}\text { Melibatkan karyawan dalam } \\
\text { perbaikan kualitas } \\
\text { Tepat waktu }\end{array}$ \\
\hline \multirow[t]{2}{*}{4.} & \multirow[t]{2}{*}{$\begin{array}{l}\text { Customer Satisfaction } \\
\text { (Kepuasan Pelanggan) }\end{array}$} & Fokus ke konsumen & $\begin{array}{l}\text { Sudah } \\
\text { diterapkan }\end{array}$ & $\begin{array}{ll}\text { Memproduksi } & \text { sesuai } \\
\text { permintaan konsumen } & \end{array}$ \\
\hline & & Manajemen yang tepat & $\begin{array}{l}\text { Sudah } \\
\text { diterapkan }\end{array}$ & Melakukan inovasi \\
\hline
\end{tabular}

Sumber: PT. Sinar Pure Foods International

Berdasarkan tabel 3, dapat diuraikan sebagai berikut:

1. Organizational practices

a. PT. Sinar Pure Foods International telah mengadakan pelatihanpelatihan atau training yang biasa disebut reorientasi, yang dilakukan dua kali dalam setahun yaitu pada bulan Februari dan Agustus.

b. PT. Sinar Pure Foods International belum mempunyai Visi dan Misi yang jelas. Karena dengan adanya Visi dan Misi, perusahaan mempunyai tujuan yang jelas dan tindakan-tindakan apa saja yang harus dilakukan untuk mencapai tujuan tersebut.

c. PT. Sinar Pure Foods International sudah mempunyai prosedur operasi yang efektif dengan adanya SOP (Standar Operasional Prosedur).

2. Quality principles. PT. Sinar Pure Foods International memiliki kerja sama yang baik. Proses total quality management tidak akan terwujud tanpa adanya kerja sama yang baik dari manajer dan karyawannya, untuk menghasilkan produk yang berkualitas dan kepuasan konsumen yang tinggi.

3. Employee fulfillment

a. PT. Sinar Pure Foods International sudah menerapkan empowerment bagi karyawan. Karena dengan menerapkan strategi ini, dapat membuat karyawan lebih punya rasa bangga terhadap pekerjaan mereka.

b. Mengenai komitmen organisasi, PT. Sinar Pure Foods International sudah memiliki komitmen jangka panjang, yang dapat digunakan untuk meningkatkan mutu perusahaan.

4. Customer satisfaction. Kepuasan konsumen merupakan bagian penting dari pelaksanaan total quality management. PT. Sinar Pure Foods International menaruh perhatian penuh terhadap konsumen. Karena kepuasan konsumen adalah yang utama sehingga perusahaan akan melakukan berbagai cara untuk meningkatkan kualitas dari produk yang dihasilkan. 


\section{Kesimpulan dan saran \\ Kesimpulan}

PT. Sinar Pure Foods International sangat memperhatikan kualitas dari produkproduk yang dihasilkan karena kualitaslah yang akan menjamin keberlangsungan hidup dari perusahaan. PT. Sinar Pure Foods International sudah menerapkan total quality management, meskipun belum mempunyai visi dan misi. Hal ini sangat berdampak bagi para pekerja dan kualitas produk yang dihasilkan.

\section{Saran}

PT. Sinar Pure Foods International harus lebih memperhatikan kinerja karyawannya, agar produk cacat yang dihasilkan semakin berkurang. Sehingga waktu yang dibutuhkan untuk proses produksi tidak terbuang percuma dan bisa mencapai target yang ditentukan. PT. Sinar Pure Foods International perlu adanya visi dan misi perusahaan. Karena visi merupakan tujuan dari perusahaan dan misi merupakan langkah-langkah yang harus dilakukan agar mencapai tujuan tersebut.

\section{Daftar pustaka}

Butarbutar, J. D., Karamoy, H., \& Tirayoh, V. Z. (2017). Analisis Penerapan Sistem Akuntansi Manajemen Terhadap Pengendalian Kualitas Produk Di PT. Empat Saudara Manado. Going Concern: Jurnal Riset Akuntansi, 12 (1), 187-193. http://doi.org/10.32400/gc.12.01.17204.2017.

Dewi, R. (2017). Akuntansi itu mudah kok. Yogyakarta: Cemerlang Publishing.

Hutauruk, M. R. (2019). Akuntansi entitas manufaktur konsep, teknik, dan aplikasi menggunakan program zahir 6, Cetakan Pertama. Yogyakarta: UPP STIM YKPN.

Helmi, Y. (2016). Pengaruh Biaya Mutu Terhadap Produk Cacat Pada CV. Reva Jaya Pratama Pekanbaru. Jurnal Mahasiswa Prodi Akuntansi Fakultas Ekonomi, 2(2), 1-10. http://ejournal.upp.ac.id/index.php/akfekon/article/vie $\mathrm{w} / 945$.

Hery. (2017). Teori akuntansi, pendekatan konsep dan analis, Edisi pertama. Jakarta: PT.Grasindo.

Hery. (2015). Pengantar akuntansi, comprehensive edition. Jakarta: PT. Grasindo.

Hery. (2014). Akuntansi dasar 1 dan 2. Jakarta: PT. Grasindo.

Janah, M. (2017). Analisis produk cacat dan produk rusak (Studi pada CV. Aneka Karya Glass Pabelan). Skripsi. http://eprints.iainsurakarta.ac.id/id/eprint/241

Jusup, A. H. (2014). Dasar-dasar akuntansi, Jilid 1. Yogyakarta: STIE YKPN.
Rachmina, D., \& Sari, S. (2015). Akuntansi manajemen, teori dan aplikasi. Jakarta: Polimedia Publishing.

Samryn, L. M. (2015). Akuntansi manajemen, edisi revisi. Jakarta: Prenada Media Group.

Santioso, L., \& Maharani, C. (2015). Analisis pengaruh penerapan total quality management dan just in time pada Industri Manufaktur (Studi empiris pada Perusahaan Manufaktur di Bogor dan Tangerang). Jurnal Ekonomi, 20(3), 371-386. http://dx.doi.org/10.24912/je.v20i3.401.

Sujarweni, V. W. (2015). Akuntansi manajemen, teori dan aplikasi. Yogyakarta: Pustaka Baru Press.

Tengor, N. L., Ilat, V., \& Tirayoh V. Z. (2016). Pengaruh Sistem Akuntansi Manajemen Terhadap Pengendalian Biaya Kualitas Produk Pada CV. Sarana Marine Fiberglass Manado. Jurnal Emba $4 \quad$ (1), 272-282. https://ejournal.unsrat.ac.id/index.php/emba/a rticle/view/11595.

Yuliansih, N. K., Nuridja, I. M., \& Tripalupi, L. E. (2014). Analisis Pengendalian Kualitas Produk Pada Perusahaan Garmen Wana Sari Tahun 2013. Jurnal Pendidikan Ekonomi Undiksha. 4(1), 112. https://ejournal.undiksha.ac.id/index.php/JJPE /article/view/4516. 